"This is a post-peer-review, pre-copyedit version of an article published in Economic Theory. The final authenticated version is available online at: http://dx.doi.org10.1007/s00199-018-1146-4"

This version is subjected to Springer Nature terms for reuse that can be found at: https://www.springer.com/gp/openaccess/authors-rights/aam-terms-v1 


\title{
Frequency of Interaction, Communication and Collusion: an Experiment*
}

\author{
Maria Bigoni $^{\dagger} \quad$ Jan Potters $^{\ddagger} \quad$ Giancarlo Spagnolo ${ }^{\S}$
}

\begin{abstract}
The frequency of interaction facilitates collusion by reducing gains from defection. Theory has shown that under imperfect monitoring flexibility may hinder cooperation by inducing punishment after too few noisy signals, making collusion impossible in many environments (Sannikov and Skrzypacsz, AER 2007). The interplay of these forces should generate an inverse U-shaped effect of flexibility on collusion. We test for the first time these theoretical predictions central to antitrust policy - in a laboratory experiment featuring an indefinitely repeated Cournot duopoly, with different degrees of flexibility. Results turn out to depend crucially on whether subjects can communicate with each other at the beginning of a supergame (explicit collusion) or not (tacit collusion). Without communication, the incidence of collusion is low throughout and not significantly related to flexibility; when subjects are allowed to communicate, collusion is significantly more frequent in the treatment with intermediate flexibility than in the treatments with low or high flexibility.
\end{abstract}

\footnotetext{
${ }^{*}$ We thank Andrzej Skrzypacz for his precious advice, and Charles Angelucci, Jeff Butler, Gabriele Camera, Martin Dufwenberg, Christoph Engel, Ernst Fehr, Tobias Klein, Wieland Mueller, Karl Schlag, Jean Robert Tyran, and participants at the European ESA Meeting in Innsbruck, the M-BEES Workshop in Maastricht, the Industrial Organization Workshop in Otranto, the CRESSE conference in Rhodes, the EIEFBologna-Bocconi IO Workshop, the ESRC London Experimental Workshop (LEW), the Amsterdam Symposium on Behavioral and Experimental Economics (ABEE), and seminars at Humbolt University Berlin, the Stockholm School of Economics, Erasmus University Rotterdam, Tilburg University, University of California Santa Cruz, IFN Stockholm, the MPI for Collective Goods in Bonn, the Technische Universität Berlin, the University of Vienna, and the University of Aix-Marseille for valuable comments. Giancarlo Spagnolo also gratefully acknowledges research funding from Konkurrensverket (the Swedish Competition Authority).

${ }^{\dagger}$ Corresponding author. University of Bologna and IZA. Piazza Scaravilli 2, Bologna, Italy, maria.bigoni@unibo.it, +39 051 2098134. ORCID: 0000-0001-5988-6115.

${ }_{\ddagger}^{\ddagger}$ Tilburg University and CentER, P.O. Box 901535000 LE Tilburg, The Netherlands.

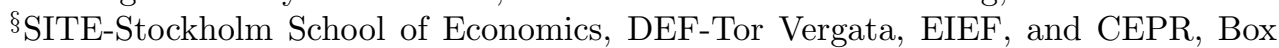
6501, 11383 Stockholm, Sweden. ORCID: 0000-0003-4117-6283.
} 
JEL: C73, C92, D43, L13, L14.

Keywords: Cartels, Cournot oligopoly, Flexibility, Imperfect monitoring, Repeated games. 
Flexibility, the ability to react swiftly to others' choices, is commonly seen as a factor that facilitates cooperation. The logic is that flexibility reduces the gains from unilateral defections by drawing punishment nearer. Axelrod, in his Evolution of Cooperation (1984, p. 129), puts it as follows: "[One] way to enlarge the shadow of the future is to make the interactions more frequent. In such a case the next interaction occurs sooner, and hence the next move looms larger than it otherwise would." Friedman and Oprea (2012) offer strong experimental support for a positive effect of flexibility on cooperation. They implement a finite horizon repeated Prisoner's Dilemma and find a strong positive relationship between the frequency with which subjects could adjust their actions and the rate of cooperation. ${ }^{1}$

Though intuitive, this established role of flexibility is theoretically robust only for games in which players can perfectly observe each others' actions. As first shown by Abreu, Milgrom and Pearce (1991), with imperfect monitoring flexibility may actually harm cooperation. The reason is that when imperfect information arrives frequently, high flexibility forces players to react to 'bad news' early, when it is still very noisy. This generates many costly mistakes which erode the value of cooperation. This negative effect of flexibility counteracts the positive effect due to the reduced gains from defection. Sannikov and Skrzypacz (2007) show in a variety of oligopolistic environments that for high levels of flexibility the negative effect dominates the positive one and renders collusion impossible. For low levels of flexibility, on the other hand, the positive effect tends to dominate the negative one and an increase in flexibility will make collusion easier. The remarkable consequence is that the impact of flexibility on the sustainability of collusion is non-monotonic.

The channel through which flexibility hinders cooperation under imper-

\footnotetext{
${ }^{1}$ In the extreme case, in which subjects could adjust their actions almost continuously, the median rate of cooperation was as high as $90 \%$. At the other extreme, in which subjects could adjust their actions only once, cooperation rates were close to zero.
} 
fect monitoring is subtle though. ${ }^{2}$ Certainly the intuition for the negative effect is less straightforward than the positive one that defection can be punished sooner. One may therefore question the behavioral relevance of the negative effect of flexibility. Does cooperation unravel with sufficiently high flexibility when monitoring is imperfect, or will the positive effect still dominate? Can one observe a non-monotonic effect of flexibility on cooperation in this case? These questions have important implications for our understanding of collusion and for antitrust policy. ${ }^{3}$ They also have implications for other settings where imperfect observability is the rule rather than the exception, such as team production, principal-agent relationships, international agreements and reputation-based market strategies (e.g. Strausz 2009).

This paper presents an experimental study designed to start answering these questions. We implement in the laboratory an indefinitely repeated quantity-setting duopoly game in discrete time with imperfect monitoring, analogous to that studied by Sannikov and Skrzypacz (2007). Players do not observe each other's quantity choices; they only observe price which is a noisy signal of total quantity. Across treatments we vary inflexibility $(\Delta)$, that is, the number of periods players have to wait before they can change quantity. The game is set up such that collusion can be supported as an equilibrium of the repeated game when $\Delta=2$, but not when $\Delta$ $=1$ or $\Delta=3$. This allows us to examine the empirical support for the effect of (in)flexibility on the incidence of collusion in the laboratory. In order to give it a fair chance, we use a simplified oligopoly game and allow

\footnotetext{
${ }^{2}$ Vives (2001) describes this result as 'counterintuitive'. One might speculate, for example, that it is possible to delay punishments until more convincing information becomes available that the other player is really defecting. Such a strategy unravels though since such a delay will strengthen the incentives of the other player to defect.

${ }^{3}$ Currently, the main IO and Antitrust textbooks present frequent interaction as a facilitating factor independently of the information agents have access to; see e.g. See Tirole (1988); Church and Ware (2000); Martin (2001); Ivaldi et al. (2003); Motta (2004); Belleflamme and Peitz (2010).
} 
for learning by having subjects play seven repetitions of the indefinitely repeated game. ${ }^{4}$

The results indicate that the current setup is very hostile to cooperation. The incidence of collusion is low throughout and not significantly related to flexibility. In order to examine whether this result may be due to coordination problems, we ran a second series of experiments in which subjects were allowed to chat with each other at the beginning of the game. There is an extensive literature, starting with Cooper et al. (1992), showing that communication facilitates coordination. Our results confirm that collusion is strongly fostered by communication in all treatments. Interestingly, when subjects are allowed to communicate, we find that the incidence of collusion is significantly higher in the treatment with intermediate flexibility than in the treatments with low or high flexibility. Also, an analysis of the contents of the chats attest to the behavioral relevance of the forces that underlie the models of Abreu et al. (1991) and of Sannikov and Skrzypacz (2007). Still, the effect of flexibility on collusion is only of second order importance relative to the effect of communication.

To the best of our knowledge this is the first experimental analysis addressing the subtle but important effects of the frequency of interaction in repeated games with imperfect monitoring. A number of recent experimental studies examine how cooperation is affected by imperfect monitoring per se. Bereby-Meyer and Roth (2006) study how imperfect monitoring interferes with learning, showing that it considerably reduces subjects' ability to learn to cooperate in repeated PD games (and to defect in one-shot ones). Aoyagi and Fréchette (2009) ask whether subjects' ability to cooperate falls when information becomes more noisy in a repeated game, finding significant support for this theoretical prediction. Fudenberg et al. (2012) look

\footnotetext{
${ }^{4}$ Several experimental papers document strong learning effects in repeated game settings (Selten and Stoecker, 1986; Camerer and Weigelt, 1988; Dal Bò and Fréchette, 2011).
} 
at the prevailing strategies in repeated games where subjects' choices are implemented with mistakes, highlighting the success of strategies that are "lenient" (do not punish the first deviation) and "forgiving" (return to cooperation after a short punishment phase). ${ }^{5}$ These studies indicate that strategies and outcomes are significantly affected by the presence of imperfect monitoring. By contrast, we take imperfect monitoring as given, and examine how it affects the comparative statics of a key structural variable.

A second novel feature of our design is the introduction of communication in a set-up characterized by imperfect monitoring. We are aware of only one, more recent paper that also combines these features. Embrey, Fréchette and Stacchetti (2014) studies the impact of renegotiation concerns in a repeated partnership game allowing for structured communication at the beginning of every period to facilitate coordination. The focus on action frequency and communication, on the other hand, relates our paper to the recent work by Oprea, Charness, and Friedman (2014) analyzing the impact of communication in continuous and discrete public goods games, although under perfect monitoring.

\section{Experimental Design}

The design of our experiment aims at replicating Sannikov and Skrzypacz (2007) [S\&S]'s intriguing theoretical results in the simplest possible setting. To do this, we adapt and further simplify their analysis of collusion in a Cournot supergame.

\footnotetext{
${ }^{5}$ See also Cason and Khan (1999), who compare perfect monitoring with perfect but delayed monitoring; and Feinberg and Snyder (2002) and Holcomb and Nelson (1997), who study the effects of different types of imperfect but private monitoring on cooperation.
} 


\section{The Game}

Two players interact repeatedly, in discrete time, in a Cournot market with homogeneous products. Players simultaneously set quantities $\left(q_{1 t}, q_{2 t}\right)$ and the resulting price depends on total quantity $\left(Q_{t}=q_{1 t}+q_{2 t}\right)$ and a random shock $\left(\epsilon_{t}\right)$. Specifically, price $P_{t}$ in period $t$ is given by:

$$
P_{t}=a-Q_{t}+\epsilon_{t}, \quad \epsilon_{t} \sim N\left(0, \sigma^{2}\right)
$$

Monitoring is imperfect because players receive information about each period's price $P_{t}$, but not about total quantity $Q_{t}$ or the random shock $\left(\epsilon_{t}\right)$. We restrict the action set to $q_{i t} \in\{3,4\}$. We set $a=12$ in the demand function, marginal cost equal to 0, and per period fixed cost equal to 16 . Table 1 presents expected price and profits of the stage game that result from this parameterization. Note that the expected profits are those of a Prisoner's Dilemma. ${ }^{6}$ Finally, we set the standard deviation of random price equal to $\sigma=1.3 .^{7}$

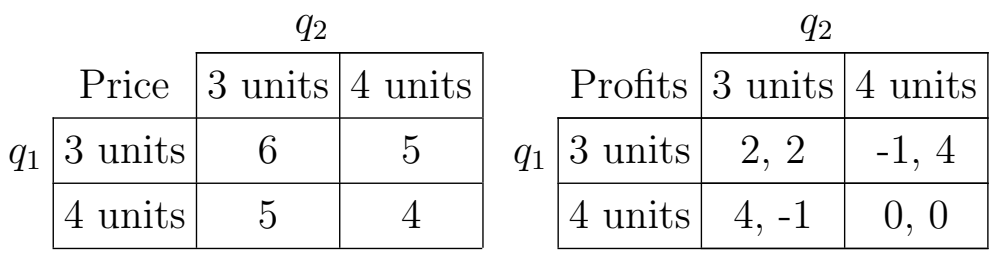

Table 1: Expected price and expected profits of the stage game.

Prices and profits materialize in every period, but quantities can be adjusted only every $\Delta$ periods. So, the quantities chosen in period $t$, together with the random shocks, determine prices and profits for the following $\Delta$ periods. A larger $\Delta$ implies that it takes longer before players can react to

\footnotetext{
${ }^{6} \mathrm{~A}$ convenient feature is that the Nash and minmax payoff are the same. This makes it easier to derive the best possible collusive outcomes.

${ }^{7}$ This implies, for example, that there is a probability of $44 \%$ that the realized price will deviate by at least 1 unit from the expected price.
} 
a (bad) price signal, but also that when they react they will have observed more signals about their opponent's quantity choice.

In the model of $S \& S$ the game is infinitely repeated and players discount future profits using a common interest rate $r$. The per-period discount factor is then equal to $\delta=e^{-r \Delta}$. In the experiment we do not implement discounting, but we implement a repeated game of indeterminate length: at the end of every sequence of $\Delta$ periods, a random draw determines whether the game ends (with probability $1-\delta$ ), or continues for additional $\Delta$ periods. (with probability $\delta$ ). Under the assumption of risk neutrality, this game is isomorphic to an infinitely repeated game where players can change their actions every $\Delta$ periods, and have a discount factor equal to $\delta$. Compared to other procedures implementing infinitely repeated games with discounting, the random termination rule leads to behavior consistent with the presence of dynamic incentives and to relatively high cooperation rates (Fréchette and Yuksel, 2014). We choose $r=0.10$ so that we have $\delta=e^{-r}=0.90$ for $\Delta=1, \delta=0.82$ for $\Delta=2$, and $\delta=0.74$ for $\Delta=3$. The continuation probability decreases with $\Delta$ but, conditional on the game being continued, the number of additional periods increases with $\Delta$. The expected number of periods is $\frac{\Delta}{1-\delta}$, which is equal to $10,11.1$, and 11.5 for $\Delta=1,2$, and 3 , respectively.

In the experiment we implement three treatments in which $\Delta$ takes the values 1,2 , and 3 , respectively. A smaller value of $\Delta$ (higher flexibility) has two contrasting effects. One is that the discount factor is higher. This implies that defection can be punished more effectively, which generates the usual positive effect on collusion. A smaller value of $\Delta$ also implies that the players attain fewer noisy (price) signals about the other player's previous action before making the next choice. This has a negative impact on the scope for collusion, since it generates a high rate of "false positives". 8

\footnotetext{
${ }^{8}$ Experiments on risk taking show that high decision flexibility may also generate
} 
The analysis of S\&S implies that the interplay between these two effects generates a non-monotonic effect of $\Delta$. Collusion can be supported as an equilibrium in the repeated game only for intermediate values of $\Delta$. When $\Delta$ is large the gains from defection are too attractive; when $\Delta$ is small the stochastic variation in prices erodes the gains from collusion by triggering too frequent punishments. In Appendix A we outline how this result can be derived. Applied to our game, assuming risk neutral payoff maximization, collusion is sustainable when $\Delta=2$, but not when $\Delta=1$ or $\Delta=3$. It is this theoretical prediction that we explore in our experiment.

\section{Procedure}

The experiment was run in the CentERlab at Tilburg University.In total, there were eighteen sessions, three for each treatment without communication, and three for each treatment with communication (see 2.1), with 16 subjects in each. ${ }^{9}$ Within each session, there were two matching groups of 8 subjects and subjects interacted only with other subjects in their matching group. Subjects were recruited through an e-mail list of students interested to participate in experiments. The experiment was computerized and programmed with zTree (Fischbacher, 2007). Interaction between subjects in the experiment was anonymous.

Upon entering the lab, subjects were randomly seated at tables separated by partitions. Written instructions were distributed and read aloud. See Appendix B for a copy of the instructions, and Appendix C for the screenshots of the program. Subjects were given ample time to study the instructions at their own pace and to privately ask questions. A short quiz was conducted to check their understanding.

a more myopic evaluation of outcomes (Gneezy and Potters, 1997). Because of the discrete design the number of expected periods (and potential collusion profits) increases slightly in $\Delta$. This could also lead flexibility to affect negatively the amount of collusion, although we believe the difference to be negligible.

${ }^{9}$ See Table D.1 in the online appendix D for further details on sessions and treatments. 
During the experiment profits were denoted in points; after the experiment points were converted into cash at a rate of 8 points $=1$ Euro. To accommodate for potential losses, subjects were given a starting endowment of 80 points. The random shocks on prices were generated by the software at the beginning of each period. ${ }^{10}$ Sessions lasted on average one hour and 45 minutes, including instructions and payment, and subjects received an average payment of 21.5 Euro. ${ }^{1112}$

Subjects were randomly matched to one other subject to play the repeated game. Below we will refer to one play of the repeated game as a match. In the first period of each match, subjects had to determine the quantity $\left(q_{i t} \in\{3,4\}\right)$ they wanted to produce. Depending on the treatment, quantities were fixed for the next $\Delta$ periods. At the end of each block of $\Delta$ periods, subjects received information about the realized prices and their own profits in the last $\Delta$ periods. The random price shock was drawn independently for each period from a normal distribution with zero mean and standard deviation $\sigma=1.3$. After each block of $\Delta$ periods, there was a probability $\delta$ that the game continued, and a probability $1-\delta$ that the game ended. When the game continued, subjects had to choose the quantity for the next $\Delta$ periods.

\footnotetext{
${ }^{10}$ The shocks were drawn independently across pairs, across periods, and across sessions. We bounded the support for the price shocks, so as to prevent prices from going negative. In theory, the probability that a shock realization makes the truncation relevant is: $0.1 \%$ if both subjects defect; $0.006 \%$ if only one subject defects; $0.0002 \%$ if both subjects cooperate. In practice in our experiment the price would have gone negative in 6 out of 11216 cases $(0.053 \%)$.

${ }^{11}$ If subjects had played non-cooperatively throughout, they would have had zero profits on average and earned only the starting endowment, amounting to 10 Euro. Playing cooperatively throughout would earn them 29.4 Euro in total in expectation. Playing the best cooperative equilibrium in $\Delta=2$ would generate expected total earnings of 23.8 Euro. This illustrates that the incentives to cooperate are substantial.

${ }^{12} \mathrm{~A}$ subject could in theory attain negative cumulative profits. The probability of this happening when subjects always defect is $3 \%$, but it is much lower when subjects cooperate. In 17 out of 1680 matches, it occurred that a subject had a negative total payoff at some point, and one subjects out of 240 ended the experiment with a negative balance, thus earning nothing. The opposite possibility, that a subject would gain an unreasonably high profit of above, say, 100 Euro, is negligible.
} 
When a game ended, a subject was rematched to a new subject to play the repeated game anew. To facilitate this rematching, the realization of the continuation probability was common across all pairs of subjects in the same session. Rematching took place 6 times. So, each subject played the indefinitely repeated game exactly 7 times, and this was common knowledge. To exclude reputation building across matches, we adopted a matching protocol that ensured that two subjects never interacted together in more than one match.

We carefully explained the details of the game and the procedure to the subjects. In particular, we took great care to explain the role of the random price shocks, the random determination of the number of periods, and the (re)matching procedure.

\section{Results}

Let us first focus on the treatments without communication. Our main interest is in how the incidence of cooperation (collusion) varies across the three treatments. We will use three different measures: the average cooperation rate across all periods in a match, the rate of cooperation in the first period of a match, and the length of initial cooperation (i.e., the last period in which a pair of players jointly decided to cooperate, before the first defection of the match took place). ${ }^{13}$ Table 2 reports averages of these measures over all matches. It is clear that the theoretical prediction is not borne out by our experimental data. There are no signs that cooperation is most prevalent in treatment $\Delta=2$. Moreover, differences between treatments are small for each of the three measures and never significant (with Wilcoxon-Mann Whitney tests using the 6 matching groups per treatment as observations).

\footnotetext{
${ }^{13}$ The length of initial cooperation is zero if at least one player defected in period 1.
} 
Table 2: Average cooperation frequencies, by treatment.

\begin{tabular}{lccc}
\hline Treatment & $\begin{array}{c}\text { Cooperation rate } \\
\text { (all periods) }\end{array}$ & $\begin{array}{c}\text { Cooperation rate } \\
\text { (period 1) }\end{array}$ & $\begin{array}{c}\text { Length of initial } \\
\text { cooperation }\end{array}$ \\
\hline$\Delta=1$ & 0.277 & 0.342 & 0.190 \\
confidence intervals & {$[0.226,0.327]$} & {$[0.284,0.401]$} & {$[0.100,0.281]$} \\
$\Delta=2$ & 0.241 & 0.250 & 0.065 \\
confidence intervals & {$[0.200,0.283]$} & {$[0.200,0.300]$} & {$[0.017,0.114]$} \\
$\Delta=3$ & 0.229 & 0.256 & 0.208 \\
confidence intervals & {$[0.191,0.267]$} & {$[0.195,0.317]$} & {$[0.059,0.357]$} \\
\hline Total & 0.249 & 0.283 & 0.155 \\
\hline
\end{tabular}

Notes: $95 \%$ confidence intervals, one observation per matching group, per match.

However, we know that aggregate comparisons may not tell the complete story because learning effects are often very important in non-trivial experimental settings (Selten and Stoeker, 1986; Camerer and Weigelt, 1988; Roth and Erev, 1995; Dal Bò and Frechétte, 2011; and Bigoni et al. 2014). We also know that the presence of imperfect monitoring may make learning even more difficult in set ups similar to ours (Bereby Meyer and Roth, 2006). The positive effect of flexibility on the sustainability of collusion is more intuitive than the negative one and less related to the information structure. We therefore expect that subjects need to gain more experience with the game before the negative effect displays its force, rather than for the positive one to act.

Figure 1 presents the development of the three measures of cooperation over the matches for each of the three treatments. The first panel gives average rates of cooperation across all periods of a match; the second panel displays the average rates of cooperation in the first period of each match; the third panel depicts the development of the length of initial cooperation. These figures confirm that, despite some differences in the initial coopera- 


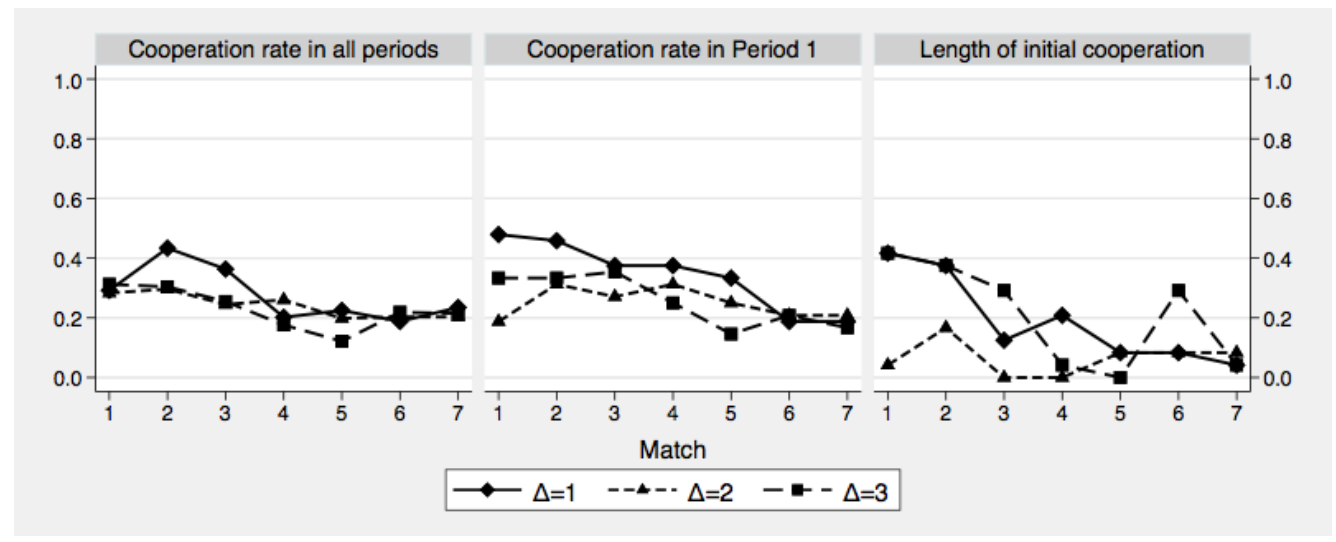

Figure 1: Measures of cooperation, across matches. Without communication.

tion rates across treatments in the first match, subjects' behavior tends to converge to very low levels of cooperation in all three treatments, and no relevant differences emerge. This impression is corroborated by the results of multivariate regressions which control for the number of the match (1 to 7) and the length of a match (which varies from 1 to 50 periods), which are presented in Table 3.

One would be tempted to interpret these results as a rejection of the theoretical predictions. However, we are dealing with infinitely repeated games where, in treatments where cooperation is sustainable in equilibrium, non-cooperation remains an equilibrium. Is the failure to cooperate/collude possibly due to a coordination problem? Subjects may simply have failed to coordinate in treatment $\Delta=2$. This would not imply a failure of the theory, which is about the existence of cooperative equilibria, not about subjects' ability to coordinate on them. An alternative explanation is that subjects adopt strategies that are fundamentally different from those predicted by the theory, which relies on the hypothesis that players play according to Grim Trigger. To test whether this is the case, we studied how subjects react to the observed signals. In a panel logit regression with fixed effects at the subject level, we estimate the impact of the average 
Table 3: Regression on initial and average cooperation.

\begin{tabular}{lcccccc}
\hline & \multicolumn{2}{c}{$\begin{array}{c}\text { Cooperation } \\
\text { period 1 }\end{array}$} & \multicolumn{2}{c}{$\begin{array}{c}\text { Cooperation } \\
\text { all periods }\end{array}$} & \multicolumn{2}{c}{$\begin{array}{c}\text { Length initial } \\
\text { cooperation }\end{array}$} \\
& M.E. & (S.E.) & M.E. & (S.E.) & Coeff. & $($ S.E. $)$ \\
\hline Match & $-0.029^{* * *}$ & $(0.008)$ & $-0.025^{* * *}$ & $(0.006)$ & $-0.399^{* *}$ & $(0.165)$ \\
$\Delta=1$ & 0.092 & $(0.063)$ & 0.010 & $(0.048)$ & 1.464 & $(1.247)$ \\
$\Delta=3$ & 0.006 & $(0.077)$ & -0.018 & $(0.048)$ & 0.961 & $(1.528)$ \\
Match's length & & & $-0.004^{* * *}$ & $(0.001)$ & -0.020 & $(0.018)$ \\
Constant & & & & & $-4.097^{* * *}$ & $(1.265)$ \\
\hline N. of observations & 1008 & & 1008 & & 504 & \\
\hline
\end{tabular}

Notes: results for period 1 are obtained via a logit regression, and results for all periods via a generalized linear model with binomial distribution and logit link function; for both regressions we report the marginal effects. Results for the length of initial cooperation are obtained via a tobit regression left-censored by 0 . In the first two regressions, we use one observation per subject, per match; in the third regression we use one observation per duopoly, per match; standard errors clustered by matching group in parentheses; symbols $*, * *, * * *$ indicate significance at $10 \%, 5 \%$, and $1 \%$, respectively.

price observed over the past $\Delta$ periods on a subject's choice to cooperate in the current period, conditional on the subject's action in the previous $\Delta$ periods. Results - reported in Table D.2 in Appendix D - suggest that in fact subjects stop cooperation when they observe a low price, and do not revert to cooperation when they are defecting and observe a high price. Figure D.1 in Appendix D further corroborates this view.

In light of these findings, we move to explore the conjecture that subjects do not cooperate in the $\Delta=2$ treatment because of a coordination issue. We hypothesize that, if we facilitate coordination among agents, then cooperation rates should go up in $\Delta=2$ where collusion is an equilibrium, but not (or at least not as much) in the other treatments. 


\subsection{Communication}

To tackle the coordination problem, we ran additional treatments with the exact same design as before but in which subjects could now communicate at the beginning of each supergame. In particular, we ran nine additional sessions with pre-play communication, three sessions for each of the three different levels of flexibility constituting our treatments, $\Delta=1,2,3$. In these new treatments, at the beginning of each repeated game a chat window opened and paired subjects could send text messages to each other for 2 minutes in free form (in English, anonymous, not offensive). When the 2 minutes expired, the chat window disappeared and subjects interacted for a sequence of periods, without any further possibility to exchange messages.

Table 4: Average cooperation frequencies. Treatments with communication.

\begin{tabular}{lccc}
\hline Treatment & $\begin{array}{c}\text { Cooperation rate } \\
\text { (all periods) }\end{array}$ & $\begin{array}{c}\text { Cooperation rate } \\
\text { (period 1) }\end{array}$ & $\begin{array}{c}\text { Length of initial } \\
\text { cooperation }\end{array}$ \\
\hline$\Delta=1$ & 0.701 & 0.893 & 2.923 \\
confidence intervals & {$[0.644,0.758]$} & {$[0.855,0.931]$} & {$[2.216,3.630]$} \\
$\Delta=2$ & 0.739 & 0.857 & 5.869 \\
confidence intervals & {$[0.688,0.791]$} & {$[0.811,0.903]$} & {$[4.043,7.695]$} \\
$\Delta=3$ & 0.660 & 0.786 & 3.095 \\
confidence intervals & {$[0.604,0.717]$} & {$[0.746,0.825]$} & {$[2.377,3.814]$} \\
\hline Total & 0.712 & 0.838 & 4.048 \\
\hline
\end{tabular}

Notes: $95 \%$ confidence intervals, one observation per matching group, per match.

Table 4 reports the aggregate cooperation data for the three new treatments with communication. First, in line with the previous literature (e.g. Fonseca and Normann, 2012; Cooper and Kuhn, 2014), it reveals that pre-play communication has an enormous impact on subjects' ability to cooperate. Average cooperation rates, for instance, increase from around 
$25 \%$ without communication (column 1, Table 2), to some $70 \%$ with communication (column 1, Table 4). The size of this effect appears even larger than typically observed in previous studies with perfect monitoring. Second, average cooperation rates and first period cooperation still offer little support for S\&S's theoretical prediction. Even though the incidence of cooperation is slightly higher in the treatment with $\Delta=2$, there appear to be no significant differences across the three treatments (with WilcoxonMann-Whitney tests using the 6 matching groups per treatment as observations). On the other hand, initial cooperation lasts significantly longer with $\Delta=2$ than under the other two treatments (Wilcoxon-Mann-Whitney tests, $\mathrm{N}_{1}=\mathrm{N}_{2}=6$, p-value $=0.016$ for the comparison between $\Delta=1$ and $\Delta=2$, and $\mathrm{p}$-value $=0.025$ for the comparison between $\Delta=2$ and $\Delta=3$ ).

Figure 2 presents the development over the matches of the average rate of cooperation, cooperation rate in period 1 , and the length of initial cooperation. The pictures reinforce the impression given by Table 4 that the length of initial cooperation is quite a bit longer in treatment $\Delta=2$ than in $\Delta=1$ and $\Delta=3$, but that cooperation rates hardly differ between treatments.

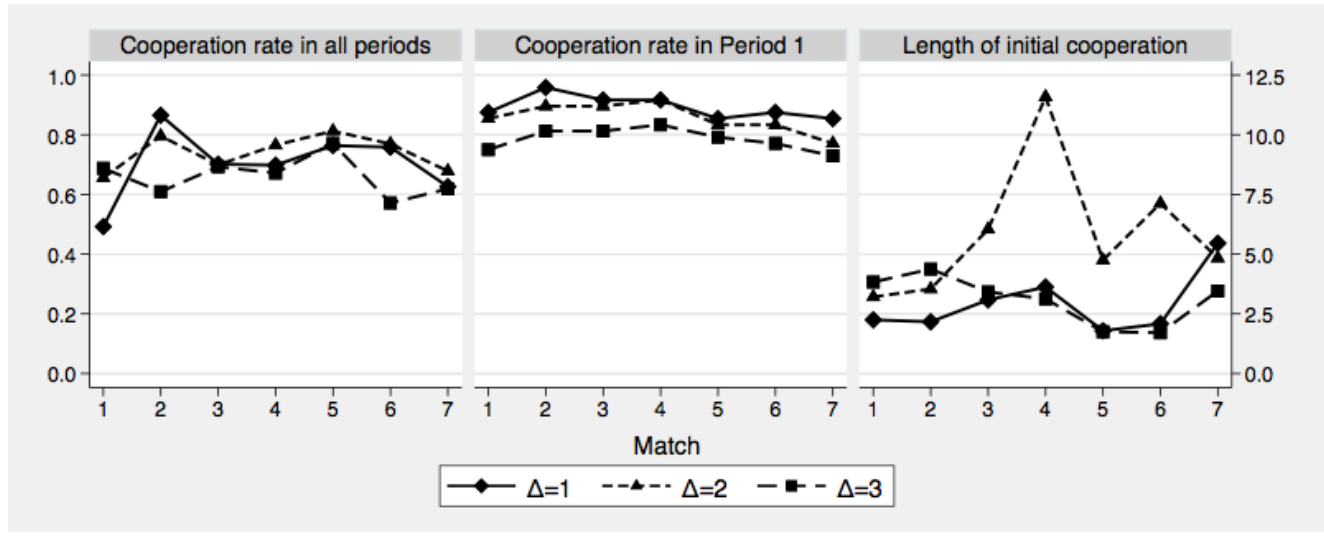

Figure 2: Measures of cooperation, across matches. With communication.

To attain further insights into these results, we ran a logit regression on cooperation in period 1 of each match, a glm regression on the individual 
cooperation rate in each match, and tobit regressions for the length of initial cooperation, in the same vein as we did for the treatments without communication. Results are presented in Table 5.

Table 5: Regression on initial and average cooperation.

\begin{tabular}{lcccccc}
\hline & $\begin{array}{c}\text { Cooperation } \\
\text { period 1 }\end{array}$ & \multicolumn{2}{c}{$\begin{array}{c}\text { Cooperation } \\
\text { all periods }\end{array}$} & \multicolumn{2}{c}{$\begin{array}{c}\text { Length initial } \\
\text { cooperation }\end{array}$} \\
& M.E. & (S.E.) & M.E. & (S.E.) & Coeff. & (S.E.) \\
\hline Match & $-0.010(0.007)$ & 0.006 & $(0.005)$ & -0.080 & $(0.192)$ \\
$\Delta=1$ & $0.036(0.058)$ & $-0.110^{* *}$ & $(0.055)$ & -1.306 & $(1.285)$ \\
$\Delta=3$ & $-0.071(0.060)$ & $-0.132^{* * *}$ & $(0.045)$ & $-2.385^{*}$ & $(1.432)$ \\
Match's length & & & $-0.007^{* * *}$ & $(0.001)$ & $0.203^{* * *}$ & $(0.061)$ \\
Constant & & & & & 1.474 & $(1.354)$ \\
\hline N. of observations & 1008 & 1008 & & 504 & \\
\hline
\end{tabular}

Notes: results for period 1 are obtained via a logit regression, and results for all periods via a generalized linear model with binomial distribution and logit link function; for both regressions we report the marginal effects. Results for the length of initial cooperation are obtained via a tobit regression left-censored by 0 . In the first two regressions, we use one observation per subject, per match; in the third regression we use one observation per duopoly, per match; standard errors clustered by matching group in parentheses; symbols $*, * *, * * *$ indicate significance at $10 \%, 5 \%$, and $1 \%$, respectively.

Table 5 reveals that cooperation rates in period 1 are not significantly different across treatments. The picture changes for cooperation beyond the first period. Once we control for the length to the match, the average cooperation rate across all periods is significantly higher in $\Delta=2$ than in the other two treatments. ${ }^{14}$ The length of initial cooperation is also sig-

\footnotetext{
${ }^{14}$ Controlling for the length of the match makes quite a difference. By chance, matches were substantially longer in treatment $\Delta=2$ than in the other two treatments, which suppressed average cooperation rates. At the same time, the length of a match has a positive effect on the length of initial cooperation. If a match ends early, any ongoing cooperation by necessity also ends. A concern one might have is that subjects overestimate the long term prospects of cooperation in treatment $\Delta=2$ if they are experiencing relatively long matches in this treatment. To check for such an effect we add the length of the previous match as a regressor to the regressions in Table 5 . This regressor is never significant though, and it only marginally affects the coefficients for $\Delta=1$ and $\Delta=3$.
} 
nificantly larger in treatment $\Delta=2$ than in treatment $\Delta=3$, while the difference between treatments $\Delta=2$ and $\Delta=1$ turns out not to be statistically significant. The general picture that emerges from these data is that, once coordination problems are solved by the possibility to communicate, cooperation beyond the first periods is significantly more prevalent in the intermediate treatment where cooperation is an equilibrium, consistent with the theoretical prediction. ${ }^{15}$

To explore further the nature of this effect, we turn to the analysis of communication content.

\subsection{Content analysis}

The striking increase in cooperation rates that we observe in all three treatments suggests that communication does not only alleviate coordination problems in $\Delta=2$, allowing subjects to cooperate more in that treatment as predicted by theory. Communication also seems to enable subjects to circumvent the forces that do not allow to sustain cooperation in equilibrium in the other two treatments. It appears able to induce subjects not to react too quickly to noisy negative signals in $\Delta=1$, and to resist the temptation to defect when $\Delta=3$. Is this reflected in the chats?

To answer this question we coded the content of the chats. Since we had 9 sessions with 7 matches in each, and 8 pairs in each match, we have 504 chats to code, with 14 lines per chat on average. We hired two graduate students, one in Tilburg and one in Rome, and let them code the chats independently after giving them the same written coding instructions (which are reported in the online Appendix E). Coders were asked to classify each

\footnotetext{
${ }^{15}$ In Table D.3 and Figure D.2 in Appendix D we replicate the analysis of subjects' reaction to observed signals, conditional on their past action. Similar to what we observed in the treatments without communication, subjects tend to switch to defection when they observe low prices. However, they are more forgiving, in the sense that the fraction of subjects who switch back from defection to cooperation tends to be higher than without communication, regardless of the observed signal.
} 
chat without knowing which treatment it belonged to. We code the chats in terms of presence/absence of five non-exclusive types of content:

Agreement: Messages confirming having reached an agreement/coordination on how to play the ensuing supergame.

Example: ${ }^{16}$ “(3,3): DDDDDDD”, “ok"

Appeal: Appeals to the partner's trustworthiness or the request for a promise to play cooperatively.

Example: "Are u a good guy?"

Promise: Promises to be trustworthy or to play cooperatively.

Example: "hah you can believe me"

Threat: Messages containing threats or forecasts of a punishment phase following non-cooperation, subdivided in: forgiving threats, and unforgiving threats.

Examples: "I will blame for the shock if the price is out of expectation for once. It it is abnormal for two periods continually I will produce 4 for 3 periods and then back to 3." (forgiving)

"once you do that I will chose 4 every period so better keep to 3 every time best for both of us" (unforgiving)

Leniency: Discussions, requests or promises of lenient behavior, in terms of waiting for more/better information before punishing a low price realization.

Example: "if you get a loss its the shock not me"

We checked inter-coder agreement using Cohen's kappa. Aggregating across all message types kappa is equal to 0.771. For each message type separately the values of kappa are somewhat lower: 0.607 (Agreement), 0.602

\footnotetext{
${ }^{16}$ The reported excerpts are taken from the subjects' communications, as classified by the coders.
} 
(Appeal), 0.644 (Promise), 0.588 (Threat), and 0.679 (Leniency). This is generally considered to be a good inter-coder agreement. In the analysis below we assign a chat to a certain category if at least one coder did so. Requiring assignment by both coders would reduce the frequency of certain categories (in particular Leniency) and impair the power of the analysis. Table 6 reports the frequency of the different classes of messages in the three treatments. ${ }^{17}$

The coordination function of communication emerges as very important in all three treatments, as more than $90 \%$ of the chats contain Agreement/coordination type messages; however, the data reveal that this type of messages is significantly more frequent in the $\Delta=2$ treatment. Interestingly, both Threats, and Leniency messages are more frequently used in $\Delta=1$, the treatment in which false-positives are predicted to erode cooperation. Indeed, if players could commit to be lenient and wait for additional information they could solve this problem and make cooperation sustainable.

Table 6: Frequency of messages by treatment.

\begin{tabular}{lcccc}
\hline \hline & $\Delta=1$ & $\Delta=2$ & $\Delta=3$ & significant differences \\
\hline Agreement & $91.1 \%$ & $94.6 \%$ & $92.9 \%$ & $1<2,2>3$ \\
Appeal & $23.2 \%$ & $29.2 \%$ & $38.7 \%$ & $\cdot$ \\
Promise & $35.1 \%$ & $30.4 \%$ & $32.7 \%$ & $\cdot$ \\
Threat & $39.9 \%$ & $20.8 \%$ & $19.0 \%$ & $1>2,1>3$ \\
Leniency & $18.5 \%$ & $9.5 \%$ & $4.8 \%$ & $1>2,1>3$ \\
\hline
\end{tabular}

Notes: category assigned if at least one coder did so; comparisons based on one-sided Mann-Whitney Wilcoxon tests, using one observation per matching group, i.e. six observations per treatment; all the emphasized differences are significant at the $10 \%$ level.

Table 7 presents the results of regressing the length of initial cooperation in a match on the use of different types of messages. The table

\footnotetext{
${ }^{17}$ The online Appendix F contains some sample chats to give an impression of how subjects used the opportunity to communicate.
} 
illustrates that particular messages are significantly related to the length of cooperation. We performed similar regression analyses using cooperation in the first period and the average rate of cooperation as dependent variables, and obtained quite consistent results. Agreements and promises are strongly associated with cooperation in all treatments, while messages discussing Leniency are most strongly related to cooperation rates in those treatments where the frequency of interaction is relatively high $(\Delta=1$ and $\Delta=2) .{ }^{18}$ Taken together, these results suggest that many subjects appreciate the main strategic forces that may erode cooperation in the different treatments as highlighted by the theory.

Table 7: Effects of communication on the length of initial cooperation.

\begin{tabular}{lcccccc}
\hline & \multicolumn{2}{c}{$\Delta=1$} & \multicolumn{2}{c}{$\Delta=2$} & \multicolumn{2}{c}{$\Delta=3$} \\
& Coeff. & $($ S.E. $)$ & Coeff. & (S.E.) & Coeff. & (S.E.) \\
\hline Agreement & $3.351^{* * *}$ & $(0.924)$ & $12.358^{* * *}$ & $(1.242)$ & $4.016^{* *}$ & $(1.585)$ \\
Appeal & -0.927 & $(1.511)$ & -0.773 & $(1.868)$ & -0.210 & $(0.734)$ \\
Promise & $1.523^{* * *}$ & $(0.436)$ & $5.055^{* *}$ & $(2.096)$ & $3.078^{* * *}$ & $(0.884)$ \\
Threat & 0.517 & $(0.533)$ & -1.653 & $(2.136)$ & -0.157 & $(1.405)$ \\
Leniency & $1.630^{* *}$ & $(0.679)$ & $8.222^{* * *}$ & $(2.369)$ & -2.000 & $(1.503)$ \\
Match & 0.088 & $(0.236)$ & -0.338 & $(0.325)$ & $-0.681^{* *}$ & $(0.294)$ \\
Match's length & $0.171^{* * *}$ & $(0.066)$ & $0.250^{* * *}$ & $(0.087)$ & $0.145^{* * *}$ & $(0.038)$ \\
Constant & -3.575 & $(2.226)$ & $-12.351^{* * *}$ & $(2.333)$ & -1.612 & $(1.544)$ \\
\hline N. of observations & 168 & \multicolumn{5}{c}{16} \\
\hline
\end{tabular}

Notes: tobit regression; one observation per pair, per match; standard errors clustered by matching group in parentheses; symbols $*, * *, * * *$ indicate significance at $10 \%, 5 \%$, and $1 \%$, respectively.

\footnotetext{
${ }^{18} \mathrm{~A}$ tobit regression pooling data from the three treatments together reveals that the effects of "Agreements" and "Leniency" are significantly smaller in $\Delta=1$ and in $\Delta=3$ than in $\Delta=2$. Regression results are available from the authors, upon request.
} 


\section{Discussion and conclusions}

We investigate the behavioral relevance of the argument, pointed out by Abreu et al. (1991) and Sannikov and Skrzypacz (2007), that incentives to cooperate may be eroded by the ability (necessity) to respond quickly to noisy information about other players' actions.

The interaction between the positive effect of flexibility on cooperation due to reduced gains from deviation and the negative effect linked to imperfect monitoring and mistakes, should generate a non-linear relationship. To test this prediction we implement, in the laboratory, an indefinitely repeated Cournot game with noisy price information similar to one of the models in Sannikov and Skrzypacz (2007), and vary how long players have to wait before changing output. In a first set of treatments we find that the theoretical prediction is not supported by the data they generate: subjects converge rapidly to very low levels of cooperation in all treatments.

This result does not support the theory, but cannot reject it either because in the intermediate flexibility treatment, where collusion is sustainable in equilibrium, many other equilibria exist. To understand whether coordination was the problem, we implement an additional set of treatments where, before the oligopoly supergames starts, subjects can communicate by exchanging text messages in free form for two minutes.

The first finding from this new set of treatments is a striking and general effect of communication: collusion rates increase three-folds in all three treatments, and the increase persists across supergames. This finding confirms and extends previous results on communication and cooperation to an imperfect monitoring environment. It suggests that communication does more than facilitating coordination. It also allows subjects to overcome the main problems that do not allow to support collusion in equilibrium in other treatments: noisy signals with high flexibility and large gains from 
defection with low flexibility.

Second, with communication collusion seems to be easier to sustain in the intermediate flexibility treatment. In other words, a non-linear relation between flexibility and collusion, albeit small, does emerge once communication is introduced. This suggests that the subtle interaction between flexibility and imperfect monitoring identified by theory is behaviorally relevant, although its effects are of second order relative to those of communication.

An analysis of the content of subjects' communication reveals a positive correlation between the frequency of other arguments subjects discuss and the main mechanism that makes collusion problematic in each treatment. In particular, we find that communication about lenient behavior, in terms of waiting for more signals before starting punishing after a low price realization, are significantly more frequent, and are positively related to collusion rates in the high flexibility treatments, i.e. in those treatments where too fast reaction to noisy information is the main problem hindering cooperation.

Our results suggest that we may want to be more nuanced in treating the frequency of interaction as a facilitating factor for collusion in markets where monitoring is imperfect and frequent. They also extend to imperfect monitoring experimental findings on the importance of communication for collusion under perfect monitoring, most recently in Fonseca and Normann (2012), and Cooper and Kuhn (2014), supporting the current antitrust practice of addressing explicit cartels (involving communication) but not tacit collusion.

Several avenues for further experimental research suggest themselves. In our design, cooperation is an equilibrium only with intermediate flexibility. Still, it could be that the incentives to cooperate do not vary enough across the different treatments to pick up strong effects. In future work, one 
could increase the incentive differences by pulling the flexibility treatments further apart, although this would make the experiment more difficult to implement because the continuation probabilities $(\delta)$ would also vary more widely. In addition, our design varies decision flexibility and communication opportunities, while keeping the rate of information feedback constant. An alternative design would be to keep action flexibility fixed, while varying the frequency of information arrival. It would be interesting to see whether such an alternative design would produce similar results, in the sense that cooperation is hindered both when information arrives very frequently and when the information lag is large (Abreu et al., 1991). It would be also important from the policy point of view to test the robustness of the results to environments with more firms and/or more frequent communication within a supergame. Another variation would be to implement different types of noisy information signals. Whereas Sannikov and Skrzypacz (2007) focus on information which arrives continuously without shocks, another relevant environment is where signals arrive discontinuously (at a Poisson rate). A testable prediction is that the impact of flexibility on cooperation will depend on the type of signal (Abreu et al., 1991). High flexibility is more harmful if the arrival rate of a signal is increasing in the rate of cooperation (the 'good news' case) than in case the arrival rate of a signal is decreasing in the rate of cooperation (the 'bad news' case). 


\section{Appendices}

\section{A Theoretical analysis}

In this Appendix we outline how the non-monotonic effect of flexibility $(\Delta)$ on the sustainability of collusion is derived. The sustainability of collusion depends on the punishment strategy adopted by the players. Nonetheless, the authors prove that it is possible to compute a robust lower bound by finding the best symmetric equilibrium with Nash reversion as a punishment, and a robust upper bound by finding the best symmetric equilibrium with the minimax payoff of 0 as a punishment. Both bounds are valid for both symmetric and asymmetric equilibria. With our parameters, the upper and the lower bound coincide, as the Nash equilibrium profit coincides with the minimax payoff in our game (both are equal to zero).

We can follow Sannikov and Skrzypacz (2007) to show that in our set up collusion $\left(q_{i}=3\right.$ ) can be sustained when $\Delta=2$, but not when $\Delta=1$ or $\Delta=3$. From Abreu et al. (1986) we know that the best strongly-symmetric equilibrium payoff of this game can be achieved by the following strategy profile:

- Players start in the collusive state and choose quantities $q_{C}, q_{C}$ (for us it will be $(3,3))$.

- As long as the realized price is in region $P_{+}$, players remain in the collusive state. If the price is outside this region, they move to the punishment state forever after.

- Because in our game mini-max has the same payoffs as the static Nash equilibrium, in an optimal equilibrium once the players reach the punishment state they play $(4,4)$ forever. 
We now characterize the region $P_{+}$and it's complement $P_{-}$. Let $G(Q)$ be the probability that the price will be in $P_{+}$, and $V$ the expected profit of the collusive equilibrium. Each player's IC constraint is:

$$
\begin{gathered}
\pi\left(q_{D}, q_{C}\right)(1-\delta)+\delta\left\{V * G\left(q_{D}+q_{C}\right)+0 *\left[1-G\left(q_{D}+q_{C}\right)\right]\right\} \leq \\
\pi\left(q_{C}, q_{C}\right)(1-\delta)+\delta\left\{V * G\left(2 q_{C}\right)+0 *\left[1-G\left(2 q_{C}\right)\right]\right\}
\end{gathered}
$$

which can be re-written as:

$$
\delta V\left[G\left(2 q_{C}\right)-G\left(q_{D}+q_{C}\right)\right]-(1-\delta)\left[\pi\left(q_{D}, q_{C}\right)-\pi\left(q_{C}, q_{C}\right)\right] \geq 0
$$

If the IC constraints are satisfied, then the expected profit in this equilibrium is:

$$
V=(1-\delta) \pi\left(q_{C}, q_{C}\right)+\delta\left[V G\left(2 q_{C}\right)+0 *\left(1-G\left(2 q_{C}\right)\right)\right]
$$

which yields:

$$
V=\pi\left(q_{C}, q_{C}\right) \frac{1-\delta}{1-\delta G\left(2 q_{C}\right)}
$$

Note that $V$ is decreasing in $\delta$ and increasing in $G\left(2 q_{C}\right)$.

Sannikov and Skrzypacz (2007) show that the optimal $P_{+}$region (that maximizes $V$ ) corresponds is a tail test. There is a cutoff $\hat{p}$ such that above $\hat{p}$ are in $P_{+}$and prices below are in $P_{-}$.

If a tail test is adopted, then

$$
G(Q)=\int_{\hat{p}}^{\infty} \phi\left[p(Q), \frac{\sigma^{2}}{\Delta}, p\right] d p
$$

where $\phi\left(\mu, \sigma^{2}, x\right)$ is the probability density function of a normal distribution with mean $\mu$ and variance $\sigma^{2}$, evaluated at $x$. Using the parametrization 
in our experiment, with $p(Q)=12-q_{1}-q_{2}$ and $\sigma=1.3$, we can rewrite the IC-constraint as a function of $\hat{p}$ and calculate when it can be satisfied at different levels of $\Delta$.

Numerical calculations show that the left-hand side of the IC-constraint (2) is convex, and that when $\Delta=2$ it is positive for cutoff prices $\hat{p} \in$ $[4.758,5.060]$, while it takes negative values for any $\hat{p} \geq 0$ when $\Delta=1$ or $\Delta=3$.

This implies that in the infinite horizon Cournot duopoly game with imperfect public monitoring collusion is sustainable in equilibrium when $\Delta=2$, while no collusive equilibrium is sustainable when $\Delta=1$ or $\Delta=3$. 


\section{B Instructions}

\section{(for on-line publication)}

In this Appendix, we report the experimental instructions for the treatment with $\Delta=3$. Instructions for the other two treatments only change where strictly necessary, and are available from the authors upon request.

Welcome to our experiment. Please follow the instructions carefully. During the experiment your earnings are denoted in points. At the beginning of the experiment you will receive an initial endowment of 80 points. In addition, you will make decisions that can make you earn or lose points. The number of points you earn depends on your decisions, the decisions of other participants, and chance. At the end, we will exchange your points into Euro according a conversion rate of 1 point $=12.5$ Eurocent, which means that 8 points $=1$ Euro. You will receive your payment privately at the end of the experiment. We guarantee anonymity with respect to other participants and we do not record any information connecting your name to your decisions or earnings.

Please be quiet during the entire experiment and do not talk to your neighbors. If you have a question please raise your hand and you will be answered privately.

\section{Your task}

\section{Production:}

You will make decisions for a firm in this experiment. For a number of periods you have to determine the quantity that your firm will produce. You can decide to produce a low level of 3 units or a high level of 4 units. Your firm operates in a market with one other firm. In each period, your profits (in points) will depend on the number of units you produce and the number of units produced by other firm. The decisions for this firm will 
be made by another participant. You cannot know who this participant is, nor can this participant know who you are. We will refer to this other participant as "the other firm". We will now explain how your profits depend on the number of units you produce and the number of units the other firm produces.

Costs:

Production involves costs. Every period, you have to pay a fixed cost of 16 points. These costs are independent of whether you produce 3 units or 4 units.

Price:

The market price in a period is the same for your firm and the other firm. The market price depends on the total production in a period. The total production is the sum of the number of units you produce, and the number of units produced by the other firm. The larger total production, the lower the market price. The expected market price is as follows:

Expected price $=12-($ number of units you produce $)-($ number of units other firm produces)

For convenience the following table summarizes how the expected market price depends on the number of units produced by your firm and the other firm.

\begin{tabular}{|c|c|c|c|}
\hline \multirow[t]{2}{*}{ Expected price } & & \multicolumn{2}{|c|}{ Production of other firm } \\
\hline & & 3 units & 4 units \\
\hline \multirow[t]{2}{*}{ Your production } & 3 units & 6 & 5 \\
\hline & 4 units & 5 & 4 \\
\hline
\end{tabular}


Profit:

Each period, your profits are equal to your revenue minus your cost, where your revenue is equal to the number of units you produce multiplied by the market price. Hence, your profit is:

Expected profit $=$ Expected price $*($ number of units you produce $)-16$

Recall that the price depends on your production and the production of the other firm. For convenience, the table below calculates how your expected profit and the expected profit of the other firm depend on your production and the production of the other firm. The first entry in each cell represents your profit, while the second entry (in gray) represents the profit of the other firm.

\begin{tabular}{|c|c|c|c|}
\hline \multicolumn{2}{|c|}{ Expected profits } & \multicolumn{2}{|c|}{ Production of other firm } \\
\hline \multirow{3}{*}{ Your production } & & 3 units & 4 units \\
\hline & 3 units & 2,2 & $-1,4$ \\
\hline & 4 units & $4,-1$ & 0,0 \\
\hline
\end{tabular}

For example, you can read in the table that if in a period you produce 3 units and the other firm produces 3 units, your expected profit will be equal to 2. You can check this as follows:

- Expected price $=12-3-3=6$

- Expected profit $=6 * 3-16=2$

You can also read in the table that if you produce 4 units and the other firm produces 4 units, your expected profit will be equal to 0 . You can check this as follows:

- Expected price $=12-4-4=4$ 
- Expected profit $=4 * 4-16=0$

Note that profit can be negative. In the unlikely event, that the total amount of points you earn in the experiment is lower than 0, you will not receive any money, but you will not have to pay any money either.

Price shocks: You may have noted that until now, we have talked about the expected price and expected profits. Due to unobservable variations in demand, the market price in a period is affected by a random shock. Specifically, the market price is the expected price plus the shock:

Price $=12-($ number of units you produce $)-($ number of units other firm produces) + shock

The price shock in one period is independent of the price shock in another period. The shock in each period is normally distributed with a mean of zero and a standard deviation of 1.3. This means that the shock is equally likely to be positive or negative. The probability that the shock attains a value in a certain range is summarized in the following table.

\begin{tabular}{lrrrr} 
Range of shock values & below -1 & -1 to 0 & 0 to 1 & above 1 \\
Probability & $22 \%$ & $28 \%$ & $28 \%$ & $22 \%$ \\
\hline
\end{tabular}

Since the mean value of the shock is zero, the expected price and the expected profit depend on the number of units produced by you and the other firm, as indicated in the tables above. The actual price and the actual profit, however, will differ as a result of the shock. For example, if your firm produces 3 units, and the other firm produces 3 units, the price will be equal to $12-3-3+$ shock $=6+$ shock, which means that the price will be 
- below 5 with probability $22 \%$

- between 5 and 6 with probability $28 \%$

- between 6 and 7 with probability $28 \%$

- above 7 with probability $22 \%$.

Now suppose the actual price shock is -0.5 . Then the actual price will be $6-0.5=5.5$ and your actual profit will be $5.5 * 3-16=0.5$, while your expected profit was 2 . Therefore, the price depends on the number of units produced by you, the number of units produced by the other firm, and the shock as follows:

Price
\begin{tabular}{|c|c|c|}
\hline & 3 units & 4 units \\
\cline { 2 - 4 } Your production 3 units & $6+$ shock & $5+$ shock \\
\cline { 2 - 4 } 4 units & $5+$ shock & $4+$ shock \\
\hline
\end{tabular}

By reducing the price a negative price shock also reduces your revenue and your profits. Conversely, a positive price shock increases your revenue and your profit. Your profits will then be:

Profit $=($ expected price + shock $) *($ number of units you produce $)-16$

It is important to realize that you have no influence whatsoever on the price shock. It is truly random. The number of units produced by you and the other firm affect the expected price, which will be higher the lower is the total production. But the actual price is also affected by the random price shock. 


\section{Periods and markets}

- You will be randomly paired to another participant for a sequence of periods, referred to as a market. This other participant will make the decisions for the other firm.

- During the whole experiment you will participate in a total of 7 markets.

- In these 7 markets you will be paired to another participant at most once.

- Every 3 periods you will have to decide how many units your firm produces in each period. This means that you will not be able to change the number of units you produce every period, but only once every 3 periods. The same holds for the other producer.

- How many periods a market will last is randomly determined. Each time three periods have been completed, the computer will randomly draw a number between 1 and 100. If the number is below or equal to 74 , the market will continue for another three periods. Hence, the probability that the market continues with the same participant for at least three more periods is $74 \%$. If the number is above 74 , a new market will start in which you will be randomly paired to another participant; unless you have already participated in 7 markets in which case the experiment will end.

\section{Information}

At the end of each period you will be informed about the number of units you produced, the price and your profits. For the periods in which you do not make a decision, this information is shown only shortly. After every block of three periods, you will also receive information on the average price 
and your average profits for the last three periods. Information from all previous periods is presented in the so-called History Table in lower part of your screen.

It is important to note that you do not receive information on the number of units produced by the other firm. You do get information on the market price, but because of the random price shock you cannot infer exactly how many units the other firm produced, nor how much profit the other firm made. Still, the price does give you some imperfect indication about the number of units produced by the other firm.

On the top left of the screen you can see how many points you have earned until now in the current market, and in the top right you can see how many points you have earned during the whole experiment, including the initial endowment of 80 points.

\section{Summary}

1. You decide how many units you wish to produce in the next three periods.

2. The number of units you produce, the number of units the other firm produces, and the price shock determine your profit in a period.

3. You are paired to one other participant for a sequence of periods, called a market.

4. After each block of three periods, there is a probability of $74 \%$ that you remain paired to the same participant for another three periods and a probability of $26 \%$ that the present market ends.

5. If a market ends you will be randomly paired to another participant and new market will start, until you have participated in 7 markets in total. 
6. The total profits you accumulate over all markets, together with the starting endowment of 80 points determine your earnings for the experiment. 8 points will be converted into 1 Euro.

\section{Procedure and questions}

You are now given some time to study the instructions on your own and to ask clarifying questions (if any). After that, you will be asked to answer a few control questions to check your understanding. The first market will start as soon as all the participants have correctly answered the control questions.

Please be reminded that you are not allowed to talk or communicate to other participants during the experiment. If you have a question, please raise your hand and I will come to your table. 


\section{Graphical interface}

(for on-line publication)

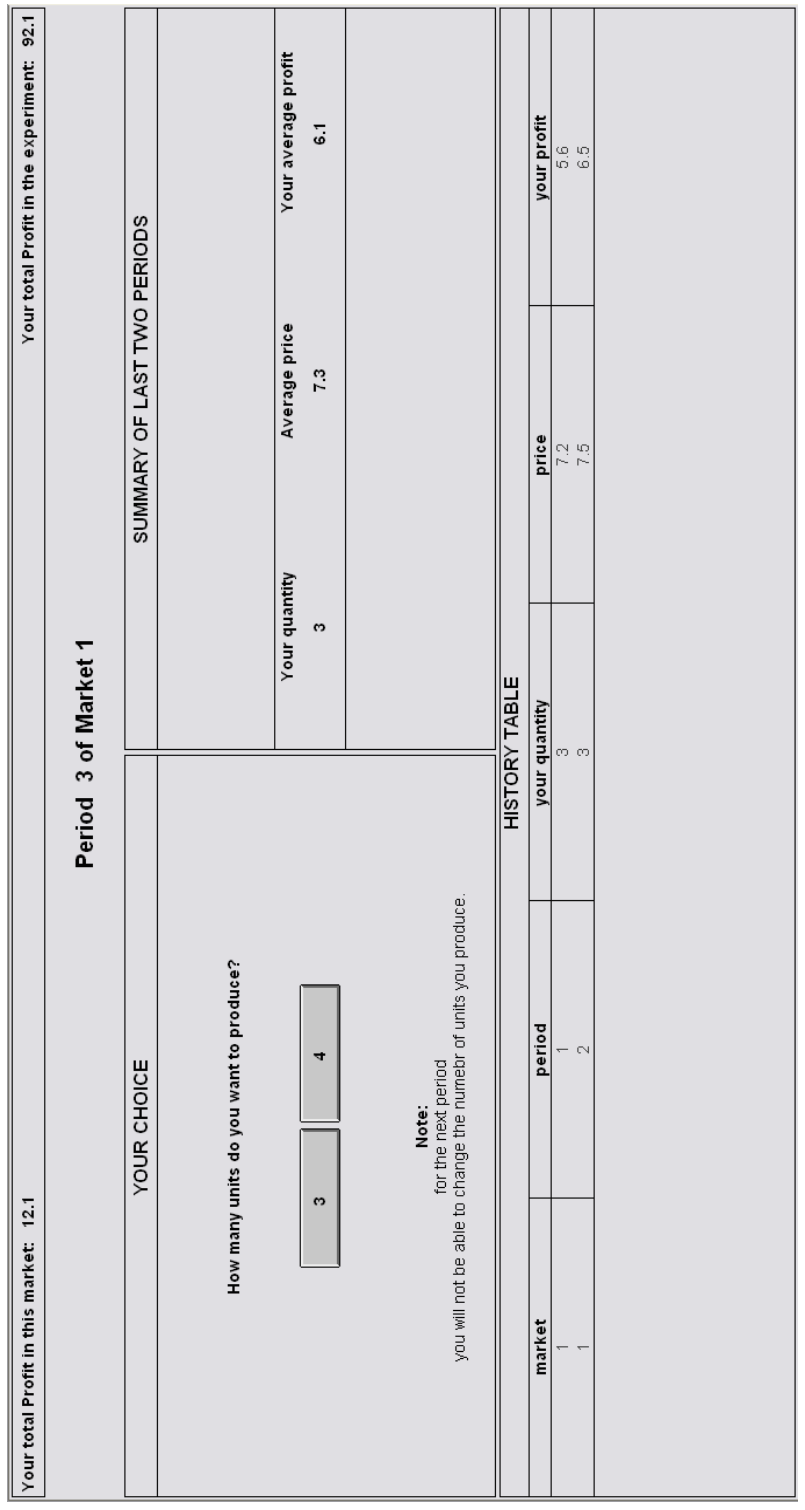

Figure C.1: Screenshot of the choice stage. 


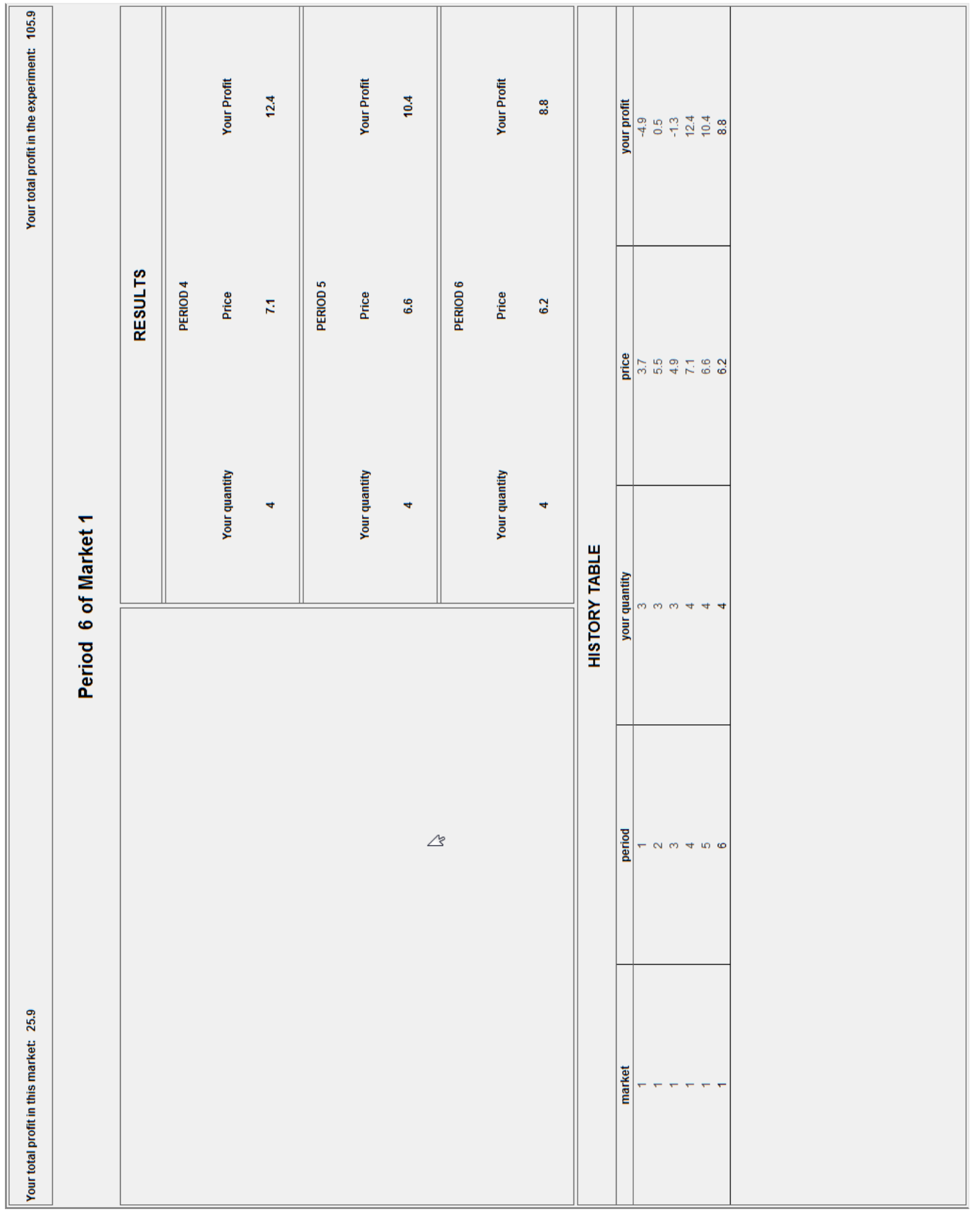

Figure C.2: Screenshot of the results stage. 


\section{Additional tables and graphs}

(for on-line publication)

\begin{tabular}{|c|c|c|c|c|}
\hline Communication & Delta & Date & Average Payment & Average match length \\
\hline \multirow[t]{9}{*}{ No } & 1 & $04 / 03 / 09$ & 13.6 & 5.9 \\
\hline & & 05/03/09 & 17.8 & 9.9 \\
\hline & & $11 / 10 / 12$ & 17.1 & 11.4 \\
\hline & 2 & 02/03/09 & 18.1 & 14.7 \\
\hline & & 05/03/09 & 17.7 & 9.3 \\
\hline & & $11 / 10 / 12$ & 18.8 & 20.4 \\
\hline & 3 & 04/03/09 & 16.6 & 9.6 \\
\hline & & 05/03/09 & 16.1 & 12.6 \\
\hline & & $10 / 10 / 12$ & 17.8 & 19.4 \\
\hline \multirow[t]{9}{*}{ Yes } & 1 & $22 / 05 / 13$ & 17.9 & 8.3 \\
\hline & & $29 / 05 / 13$ & 21.6 & 10.7 \\
\hline & & $23 / 11 / 17$ & 23.4 & 10.9 \\
\hline & 2 & $22 / 05 / 13$ & 35.9 & 22.7 \\
\hline & & $29 / 05 / 13$ & 30.8 & 14.4 \\
\hline & & $23 / 11 / 17$ & 25.2 & 15.3 \\
\hline & 3 & $22 / 05 / 13$ & 21.9 & 7.0 \\
\hline & & $29 / 05 / 13$ & 24.8 & 10.4 \\
\hline & & $23 / 11 / 17$ & 25.6 & 18.1 \\
\hline
\end{tabular}

Table D.1: Sessions details. 


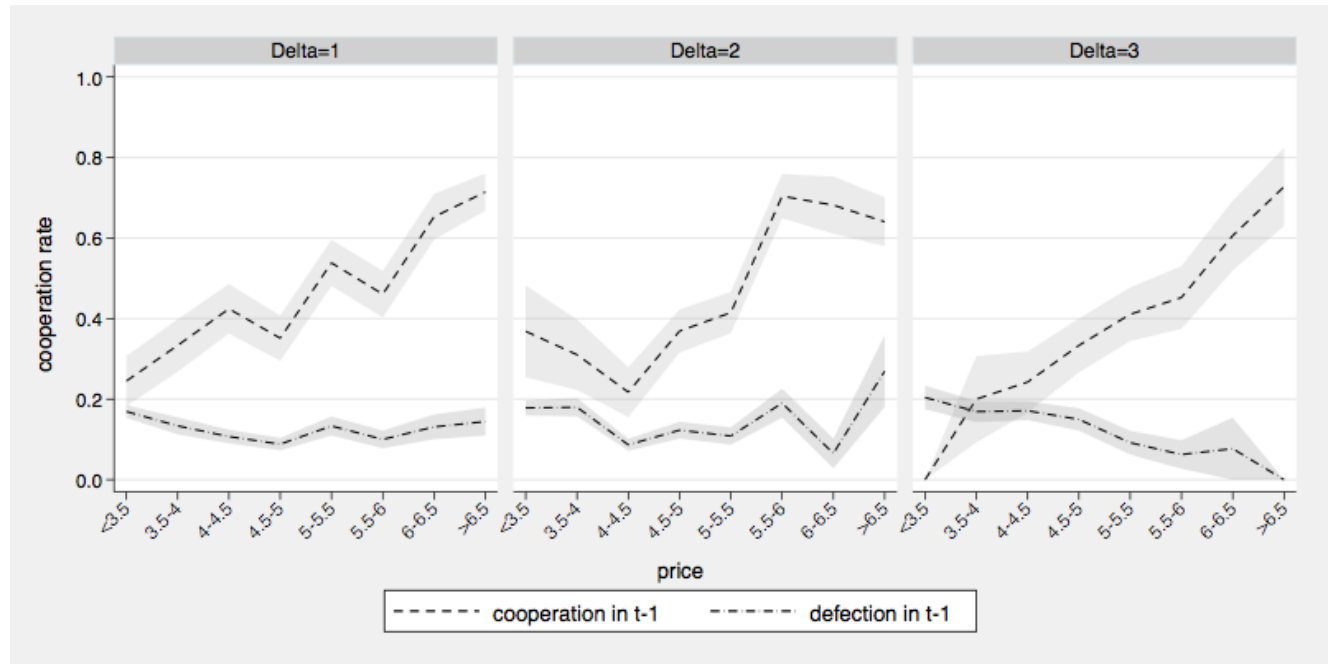

Figure D.1: Average cooperation rate, conditional on past signal and action. Treatments without communication.

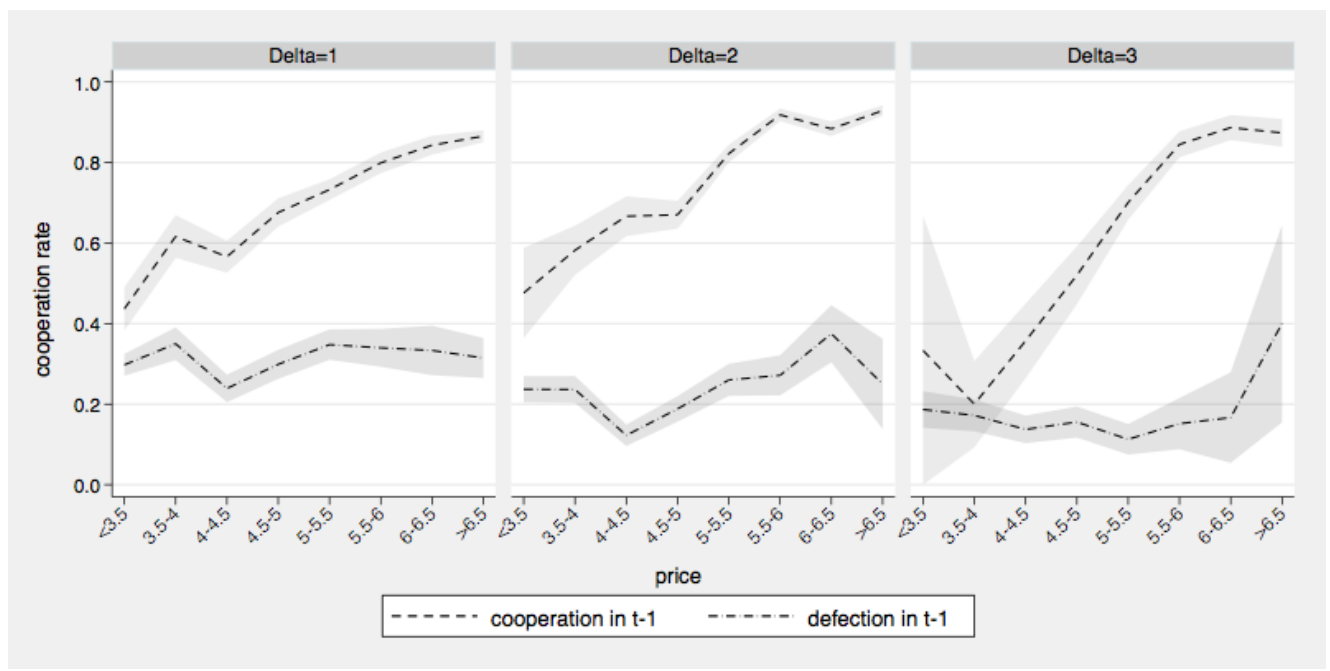

Figure D.2: Average cooperation rate, conditional on past signal and action. Treatments with communication. 


\begin{tabular}{|c|c|c|c|c|c|c|}
\hline & \multicolumn{2}{|c|}{$\Delta=1$} & \multicolumn{2}{|c|}{$\Delta=2$} & \multicolumn{2}{|c|}{$\Delta=3$} \\
\hline $\operatorname{Coop}_{t-1}$ & $-0.258^{* * *}$ & $(0.046)$ & $-0.374^{* * *}$ & $(0.067)$ & $-0.365^{* * *}$ & $(0.118)$ \\
\hline Price $_{t-1} \times \operatorname{Coop}_{t-1}$ & $0.102^{* * *}$ & $(0.022)$ & $0.132^{* * *}$ & $(0.028)$ & $0.200^{* * *}$ & $(0.058)$ \\
\hline Price $_{t-1} \times$ Def $_{t-1}$ & $-0.032^{* * *}$ & $(0.009)$ & $-0.032^{*}$ & $(0.017)$ & $-0.087^{* * *}$ & $(0.020)$ \\
\hline Match & $-0.024^{* * *}$ & $(0.005)$ & $-0.023^{* * *}$ & $(0.006)$ & -0.007 & $(0.010)$ \\
\hline Period in match & $-0.010^{* * *}$ & $(0.002)$ & -0.005 & $(0.003)$ & -0.007 & $(0.007)$ \\
\hline N. of observations & 2597 & & 2041 & & 1193 & \\
\hline
\end{tabular}

Notes: Marginal effects from a panel logit regression with fixed effects at the subject level. One observation per subject, per $\Delta$ periods. Symbols $* * *, * * *$ indicate significance at $10 \%, 5 \%$, and $1 \%$, respectively.

Table D.2: Cooperation depending on past signals and actions. Treatments without communication.

\begin{tabular}{lcccccc}
\hline & \multicolumn{2}{c}{$\Delta=1$} & \multicolumn{2}{c}{$\Delta=2$} & \multicolumn{2}{c}{$\Delta=3$} \\
\hline Coop $_{t-1}$ & $-0.270^{* * *}$ & $(0.081)$ & $-0.186^{* *}$ & $(0.091)$ & $-0.826^{* * *}$ & $(0.096)$ \\
Price $_{t-1} \times$ Coop $_{t-1}$ & $0.064^{* * *}$ & $(0.006)$ & $0.028^{* * *}$ & $(0.007)$ & $0.077^{* *}$ & $(0.034)$ \\
Price $_{t-1} \times \mathrm{Def}_{t-1}$ & 0.007 & $(0.006)$ & $0.006^{* *}$ & $(0.003)$ & -0.004 & $(0.012)$ \\
Match & $0.014^{* * *}$ & $(0.003)$ & $0.004^{* * *}$ & $(0.001)$ & -0.003 & $(0.004)$ \\
Period in match & $-0.008^{* * *}$ & $(0.002)$ & $-0.002^{* *}$ & $(0.001)$ & -0.005 & $(0.004)$ \\
\hline N. of observations & 3008 & & 2577 & & 984 & \\
\hline
\end{tabular}

Notes: Marginal effects from a panel logit regression with fixed effects at the subject level. One observation per subject, per $\Delta$ periods. Symbols $*, * *, * * *$ indicate significance at $10 \%, 5 \%$, and $1 \%$, respectively.

Table D.3: Cooperation depending on past signals and actions. Treatments with communication. 


\section{E Coding instructions}

\section{(for on-line publication)}

Your task is to classify or "code" the messages exchanged through a computerized chat system by subjects that participated to a laboratory experiment. The experiment was designed to study how perturbed/noisy information, the ability to react fast to the choices of a partner/opponent, and the possibility to communicate affect subjects ability to sustain cooperative behavior (in experimental oligopoly games).

Flexibility, the ability to react swiftly to others' choices, is commonly seen as a factor that facilitates cooperation. The intuitive logic behind this belief is that flexibility reduces gains from cheating on the promise to cooperate by drawing the punishment/reaction of the cheated opponent nearer. Though appealing and intuitive, this established role of flexibility may have negative effects on cooperation where there is only imperfect monitoring of each others actions, so that each subject is not certain whether the partner/opponent cheated or some random shock determined the bad outcome. The reason is that when there is imperfect information that arrives frequently, high flexibility may induce players to react to bad news' too early, when they are still very imprecise, rather than waiting for more information before reacting. This generates many costly mistakes which erode the value of cooperation and the ability to sustain it.

To test the empirical relevance of these different effects we implemented in the laboratory an indefinitely repeated quantity-setting duopoly game with imperfect monitoring. Subjects played a game (that is described in the enclosed instructions) in pairs. They played this game several times, and each time they were matched randomly and anonymously with one of the other subjects. In this game, subjects could choose the quantities they produce and thereby influence the market price, which was determined by 
the sum of both subjects' output. Choosing to produce a high quantity, 4, led to larger individual sales, but depressed the market price for both players. Therefore, subjects could prefer to cooperate and both choose low output, 3, so that prices stay high and both subjects gain higher profits. Of course, if one subject chose to cooperate keeping output low, producing 3, the other could cheat instead of cooperating, choosing a larger output, 4, and earning a higher individual profit by exploiting the first subjects cooperative attempt to keep the price high by producing only 3 . That is, cooperating by choosing low output 3 could be exploited by the opponent who could cheat by choosing the high production level 4 hoping not to be detected because of the imperfect monitoring.

As mentioned, cheating could go undetected because the market price was not only affected by the quantities, it was also influenced by an unobservable random shock that made it difficult to understand if in the previous period the partner chose to cooperate (i.e. to keep output low, at 3, so that the market price stayed high) or chose instead to cheat and make more by producing high output 4 while the other cooperated producing only 3. Subjects could not observe each other's quantity choices; they only observed price which is a noisy signal of total quantity, so they could never be completely sure that a low price was due only to bad luck or also to the opponent failing to cooperate. But of course if the price stayed consistently very low for many period it was more likely that the opponent was producing high quantity. Across treatments we varied the number of periods players have to wait before they can change quantity.

Crucially, at the beginning of each oligopoly games (in the treatments that you will code), subjects could also communicate in a chat. We are interested in understanding what type of messages they exchanged in the different chats, and whether the typical messages change across treatments with different levels of flexibility. Your task is to categorize the content of 
these chat messages in the way explained below.

The next page reports detailed guidelines (Coder guidelines) on how to code the chat messages. The attached excel file contains the chats and the columns on the right side that you will need for the coding. The guidelines should (hopefully) become much clearer if you read them again after you have looked at some of the chats.

Once you start coding, you will understand better how to code, and you may realize that some of the earlier code were not exactly how you wanted. It is no problem to revise earlier coding decisions if - after you have gained some experience - you realized that you should have coded differently some of the early chats.

We also attach the instructions we distributed to subjects before they played the game in case you want to know more precisely how the game was described to subjects and played. 


\section{Coding guidelines}

We want to know whether or not one or both subjects exchange messages of the following type:

\section{A. Messages confirming having reached an agreement/coordination on a common plan for the current game (not in the past) to co- operate on the choice of quantities.}

Examples:

- after one subject proposes to chose some quantities 3,3 (or 4,4 , or $3,4$, or 4,3$)$, the other replays "yes" or "OK" or, "let's chose it", or "agreed," or "choosing 3,3, is fine for me", or " $3-3$ it is. that is what I was thinking."

- after one subject proposes to chose low quantities, e.g. to keep up the price, the other replays "yes", or "OK", or "agreed", etc.

If one subject sends a message of this type in a line of the chat reported in the attached excel file, please put a 1 on the same row correspondent to that message in column A, correspondent to "agreement/coordination".

\section{B. Messages containing an appeal to the opponent's trustwor- thiness or a request for a promise by the opponent to cooper- ate/respect an agreement/not to cheat. \\ Examples: "please do not cheat"; "can I trust you?"; "promise you will stick to the agreement." \\ If one subject sends a message of this type, please put a 1 on the line correspondent to the message in column B, correspondent to "request of trust/promise."}

C. Messages in which the sender of the message explicitely promises/states that he will be cooperate or will be trustworthy. 
Examples: "I will play 3." "I will not fight." "you can trust me." "I will not let you down."

If one subject sends a message of this type, please put a 1 on the line correspondent to the message in column C, correspondent to "promise/statement of trustworthiness."

D. Messages containing a threat, a promise or forecast that some punishment will follow a choice not to cooperate

Examples: "otherwise there is tit-for-tat." "if I see several price with price close to 5 I will change", "if one of us tries to get advantage, the other will notice at some point and it will go to hell."

If one subject sends a message of this type, please put a 1 on the line correspondent to the message in column D, correspondent to "threat/punishment."

D1. Messages containing a forgiving threat, i.e. specifying that the punishment will have a limited duration, after which it is possible to go back to cooperation.

Example: "if one of us choose 4 units instead of 3, the next two period, we can choose 4 units to punish each other"

If one subject sends a message about a treat/punishment specifying that the punishment will only be lasting a limited time, then - besides putting a 1 in column D as explained above - please put also a 1 on the line correspondent to the message in column D1 correspondent to "forgiving threat."

D2. Messages containing an unforgiving threat, i.e. specifying that the punishment will have unlimited duration, it will go on until the end of that match.

Example: "once i am noticing that you are rolling for 4, i will continue to choose 4 until the end of the market" 
If one subject sends a message about a treat/punishment specifying that the punishment will last forever/until the end of the match, then besides putting a 1 in column $\mathrm{D}$ as explained above, please put also a 1 on the line correspondent to the message in column D2 correspondent to "unforgiving threat."

E. Messages requesting, promising or discussing lenient behavior, i.e. waiting for more signals before punishments until better information arrives.

Example: "even if under negative shock, we should persist on choose 3" If one subject sends a message about leniency, please put a 1 in column E correspondent to "lenient behavior."

Finally, it is fine to enter multiple 1's in a column if more than one line of the same chat falls within a certain category. 


\section{F Examples of chats}

Session 12, group 1 , match $4 ; \Delta=3$.

Subject 5: hi

Subject 1: hello

Subject 5: so this is a prisoners dilemma

Subject 1: yes

Subject 1: waht do you suggest?

Subject 5: as long as we both constantly produce 3 units we will end up with the most profits

Subject 1: yes that is true

Subject 5: so both 3 ?

Subject 1: but can i trust you to produce 3?

Subject 5: yes you can trust me

Subject 1: okay

Subject 5: i can trust you?

Subject 1: when i think you did not play 3 , i will start playing 4

Subject 1: but if you play 3 you can trust me to do the same

Subject 1: that gives the most profits

Subject 5: okay I promise I play 3

Subject 1: so lets do that!

Subject 5: yes

Session 13, group 6, match $4 ; \Delta=1$. 
Subject 14: hi

Subject 14: let's stick to 3?

Subject 10: hello. yes 3 it is

Subject 14: great

Subject 14: whenever the price goes below 5, though, I will change to 4

Subject 14: and after I'll keep on with 3

Subject 14: do you have strategy about this?

Subject 10: welllll price will easily get below 5 .

Subject 14: then we have to secure our profit

Session 15, group 4, match $5 ; \Delta=2$.

Subject 4: Hi there

Subject 7: hi,cooperate?

Subject 4: yes please

Subject 7: i trust you, so please trust me too, and we can see the truth from the results

Subject 4: If price doesn't fluctuate around 6, you are not cooperating and i will start producing 4 as well

Subject 7: ok....

Subject 4: hope I can trust you as welll

Subject 7: but sometimes the shock may mislead, so we need to insist....

Subject 4: anyway, Keep the shocks in mind

Subject 4: true, i don't stop 3 after 1 round 
Subject 4: but based on more rounds

Subject 4: Hope you honest

Subject 7: yes, you are right

Subject 7: ** 


\section{References}

Abreu, D., P. Milgrom, and D. Pearce (1991), "Information and Timing in Repeated Partnerships", Econometrica, 59, 1713-1733.

Abreu, D., D. Pearce, and E. Stacchetti (1986), "Optimal Cartel Equilibria with Imperfect Monitoring", Journal of Economic Theory, 39, 251-269.

Aoyagi, M., and G. Fréchette (2009), "Collusion as Public Monitoring Becomes Noisy: Experimental Evidence," Journal of Economic Theory, 144, 1135-1165.

Axelrod, R. (1984), The Evolution of Cooperation, New York: Basic.

Belleflamme, P., and M. Peitz, (2010), Industrial Organization: Markets and Strategies, Cambridge: Cambridge University Press.

Bereby-Meyer, Y., and A. Roth, (2006), "The Speed of Learning in Noisy Games: Partial Reinforcement and the Sustainability of Cooperation", The American Economic Review, 96, 1029-1042.

Bigoni, M., Casari, M., Skrzypacz, A., and Spagnolo, G. (2015), "Time Horizon and Cooperation in Continuous Time," Econometrica, 83(2), 587616.

Camerer, C., and K. Weigelt (1988), "Experimental Tests of a Sequential Equilibrium Reputation Model," Econometrica, 56, 1-36.

Cason, T., and F. Khan (1999), "A Laboratory Study of Voluntary Public Goods Provision with Imperfect Monitoring and Communication," Journal of Development Economics, 58, 533-552.

Church, J., and R. Ware (2000), Industrial Organization. A Strategic Approach, McGrawHill. 
Cooper, R., DeJong, D. V., Forsythe, R., and Ross, T. W. (1992). "Communication in coordination games," The Quarterly Journal of Economics, 739-771.

Cooper, D. J., and Kuhn, K.-U. (2014), "Communication, Renegotiation, and the Scope for Collusion," American Economic Journal: Microeconomics, 6, 247-278.

Bò, P., and G. Fréchette (2011), "The Evolution of Cooperation in Infinitely Repeated Games: Experimental Evidence," American Economic Review, 101, 411-429.

Embrey, M.; Fréchette, G. R., and Stacchetti, E. (2014), "An Experimental Study of Imperfect Public Monitoring: Efficiency Versus RenegotiationProofness," Available at SSRN 2346751.

Feinberg, R., and C. Snyder (2002), "Collusion with secret price cuts: An experimental investigation," Economics Bulletin, 3, 1-11.

Fischbacher, U. (2007), "z-Tree: Zurich Toolbox for Ready-made Economic Experiments", Experimental Economics, 10, 171-178.

Fonseca, M. A., and Normann, H.-T. (2012), "Explicit vs. tacit collusionThe impact of communication in oligopoly experiments," European Economic Review, 56, 1759 - 1772.

Fréchette, G., and Yuksel, S. (2017), "Infinitely Repeated Games in the Laboratory: Four Perspectives on Discounting and Random Termination," Experimental Economics, 20(2), 279-308.

Friedman, D., and R. Oprea (2012), "A Continuous Dilemma", American Economic Review, 102, 337-363. 
Fudenberg, D., D. Rand, and A. Dreber (2012), "Slow to Anger and Fast to Forgive: Cooperation in an Uncertain World", American Economic Review, 102(2), 720-749.

Gneezy, U., and J. Potters (1997), "An Experiment on Risk Taking and Evaluation Periods", Quarterly Journal of Economics, 112(2), 631-645.

Holcomb, J.H., and P.S. Nelson (1997), "The Role of Monitoring in Duopoly Market Outcomes", Journal of Socio-Economics, 26(1), 79-93.

Ivaldi, M., B. Jullien, P. Rey, P. Seabright, and J. Tirole (2003), "The Economics of Tacit Collusion," Final Report to DG Competition, European Commission, av. from

http://ec.europa.eu/competition/mergers/studies_reports/

the_economics_of_tacit_collusion_en.pdf

Martin, S. (2001), Industrial Organization in Context, Oxford: Oxford University Press.

Motta, M. (2004), Competition Policy: Theory and Practice, Cambridge: Cambridge University Press.

Oprea, R., Charness, G., and Friedman, D. (2014), "Continuous Time and Communication in a Public-goods Experiment," Journal of Economic Behavior and Organization, 108, 212-223.

Roth, A. \& Erev, I. (1995), "Learning in extensive-form games: Experimental data and simple dynamic models in the intermediate term" , Games and Economic Behavior 8(1), 164-212.

Sannikov, Y., and A. Skrzypacz (2007), "Impossibility of Collusion under Imperfect Monitoring with Flexible Production," American Economic Review, 97, 1794-1823. 
Selten, R., and R. Stoecker (1986), "End Behavior in Sequences of Finite Prisoner's Dilemma Supergames: A Learning Theory Approach," Journal of Economic Behavior and Organization, 7, 47-70.

Strausz, R. (2009), "Planned Obsolescence and the Provision of Unobservable Quality," The Economic Journal, 119, 1405-1421.

Tirole, J. (1988), The Theory of Industrial Organization. Cambridge, Massachusetts: MIT Press.

Vives, X. (2001) Oligopoly Pricing. Old ideas and new tools. Cambridge, Massachusetts: MIT Press. 